Lennartsson, M., and Elgh, F. (2018). "Exploring requirements in product development within industrialized house-building to facilitate a platform strategy" In: Proc. $26^{\text {th }}$ Annual Conference of the International. Group for Lean Construction (IGLC), González, V.A. (ed.), Chennai, India, pp. 538-548. DOI: doi.org/10.24928/2018/0283. Available at: www.iglc.net.

\title{
EXPLORING PRODUCT DEVELOPMENT IN INDUSTRIALIZED HOUSING TO FACILITATE A PLATFORM STRATEGY
}

\author{
Martin Lennartsson', Fredrik Elgh ${ }^{2}$
}

\begin{abstract}
Industrialized house-building companies are offering unique products by adopting an engineer-to-order (ETO) strategy. Client satisfaction is achieved by adaptation of product solutions and swift introduction of new technology in combination with cost-efficient production and short lead-time for completion. Product development is executed in collaboration with the clients and changes in requirements are frequent. The use of product platforms, where external and internal efficiency are well-balanced, has been acknowledged as a strategic enabler for mass customization and increased competitiveness. However, ETO-companies struggle with adopting the common product platform approach, set by pre-defined modules and components. Predefinitions may cause an imbalance between product development and a lean production system. The aim of this work was to analyse current strategies and support to master the balance of external and internal efficiency in product development within industrialized housebuilding to facilitate the development of a product platform strategy. Data were gathered from a single case study and an on-going product platform development and includes interviews and document analysis. The findings show that product development is guided by a technical platform, but there is an imbalance where external efficiency is prioritized over the internal efficiency.
\end{abstract}

\section{KEYWORDS}

Product development, Industrialised house-building, Engineer-to-order, Product platform

\section{INTRODUCTION}

Industrialized house-building is a complex field, consisting of several constructs that need to be integrated and continuously developed (Lessing et al. 2015), where the building system is a key asset (Johnsson 2011). Further, Lessing et al. (2015) stress that industrialized house-building needs to be managed strategically and not on a building

1 Assistant Prof., Jönköping University, School of Engineering, Jönköping, Sweden. +46-36-101631, martin.lennartsson@ju.se

2 Prof., Jönköping University, School of Engineering, Jönköping, Sweden. +46-36-101572, fredrik.elgh@ju.se 
project level. The challenge for house-building companies is to balance standardisation and customisation to reduce uncertainty in the supply chain (Gosling et al. 2013).

Construction is identified as a sector employing an Engineer-to-order (ETO) production strategy (Gosling and Naim 2009). In recent years, there has been an increasing focus on the platform concept in the construction sector (Johnsson 2013; Jansson 2013; Jensen et al. 2012; Thuesen and Hvam 2011). A generally accepted definition from Robertson \& Ulrich (1998) describes product platforms as "The collection of assets [i.e., components, processes, knowledge, people and relationships] that are shared by a set of products", not only including artifacts in the concept. Through product platforms, companies achieve high levels of product variety, a reduced time to market, improved operational efficiency and responsiveness to market needs (Meyer and Utterback 1993, Muffatto 1999). Improved customer value is targeted by adaptation of product solutions and swift introduction of new technologies combined with cost-efficiency and lead-time reduction. The use of a product platform, where external and internal efficiency are well balanced, has been acknowledged as a strategic enabler for mass customization and increased competitiveness.

However, ETO-companies struggles with adopting the common platform approach building upon pre-defined modules and components. By applying the core competences of ETO (Konijnendijk 1994), Johnsson (2013) scrutinized product development platforms in house-building concluding that coordination between market and manufacturing is a crucial capability when engaging in platform organisation. Jensen (2014) investigated platform architecture and modularity within construction and the results show that for an ETO-based context and integrated product architecture it is difficult to apply platforms. Still, by approaching the problem from a modify-to-order/configure-to-order perspective platform theory can be applied by incremental development. From a platform perspective, Jansson (2013) studied the design phase and stresses that when an ETO strategy is applied, the balance between distinctiveness and commonality is crucial to master.

The aim of this work is to analyse current strategies and support to master the balance of external and internal efficiency in product development within industrialized housebuilding to facilitate the development of a product platform strategy. Empirical data were gathered from a case study of an industrialized house-building company and includes interviews and document analysis, where the product development process was scrutinized from a platform strategy perspective.

\section{METHOD}

To achieve the aim of the paper two data collection methods were used: interviews, and analysis of internal documents from the case company. A case study is appropriate since it involves studying a phenomenon in its natural context, targeting rich descriptions of the phenomenon (Miles and Huberman, 1994). A set of semi-structured interviews regarding the current product development process was conducted. The questions were separated into different domains: product and technology development before and after order point; demands; information sources, tools and models; process development and; platforms. Five respondents (technical manager, structural manager, HVAC coordinator, electricity 
coordinator and design coordinator) with key responsibilities were chosen to obtain a comprehensive representation of the current practice. To support the data collected from the interviews, internal documents describing the current platform strategy for product development was scrutinized. The primary source is the technical platform, where product families and house models are described. Types of documents include, drawings needed to produce standard configurations, but also design templates and standard operations (STD), which describe a variety of issues, e.g. technical solutions, bill of material and way of working. Further, the data analysis was guided by the theoretical framework and the representations from Robertson and Ulrich (1998) and Krause et al. (2014).

\section{CASE DESCRIPTION}

The studied company is focusing on products such as, schools, kindergartens, elderly homes and offices, which demands knowledge of their client operations. The company applies an industrialized house-building strategy and off-site construction with up to $90 \%$ of completion in a factory and follows the process described in Johnsson and Meiling (2009). Thus, a fundamental idea is to maintain a high level of standardisation in the production. The building system is based on volumetric elements in turn-key contracts, meaning that the company is covering all disciplines and the entire construction process. However, clients are often municipalities and other public actors having large budgets and also the capacity to either set a narrow frame of demands, making it hard to fit the building system, or to continuously alter the demands on the projects. In consequence, the company is an appropriate choice to investigate internal and external efficiency. The on-site assembly and kindergarten project is illustrated in fig. 1.

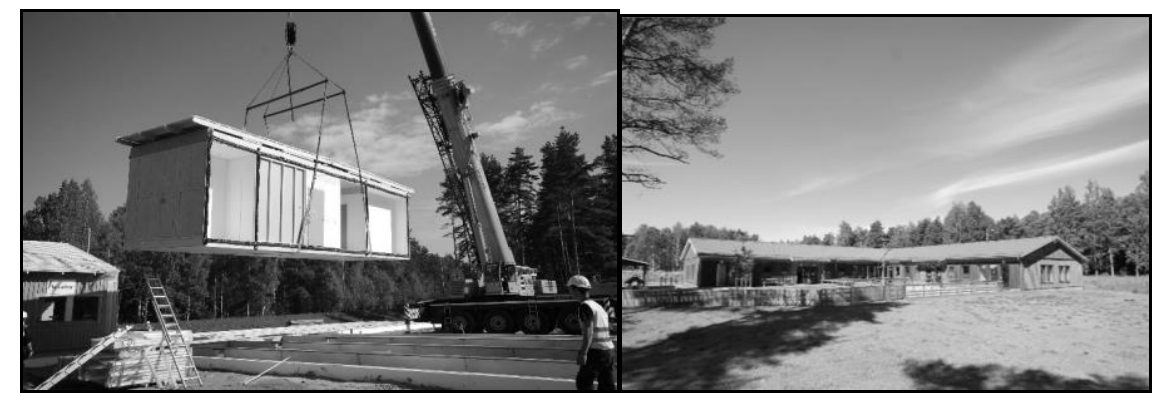

Figure 1: On-site assembly of volume elements and a finished kindergarten project.

\section{THEORETICAL FRAMEWORK}

\section{PLATFORM THEORY}

Beside Robertson and Ulrich (1998), other definitions of product platforms can be found. McGrath, (1995) describes the concept as "A collection of common elements, especially the underlying core technology, implemented across a range of products". Thus, adding technology to be a fundament, which can be connected to the building system concept (Johnsson 2011). Simpson et al. (2006) add a competitive aspect by saying "group of related products that is derived from a product platform to satisfy a variety of market niches". Meyer and Lehnerd (1997) include a market aspect and propose "A set of 
common components, modules, or parts from which a stream of derivative products can be efficiently developed and launched". Both Simpson et al. (2006) and Meyer and Lehnerd (1997) include competitiveness as a key element. Thus, when combining customized product offers with a platform approach, the challenge is to stay competitive, in other words, balancing external and internal efficiency.

Further, Krause et al. (2014) proposes a toolkit to use in design to keep the external variety high at the same time keeping the internal variety low. Four principles outline the basis of the proposed toolkit: Clear differentiation between standard components and variant components, reduction of the variant components to the carrier of differentiating properties, one-to-one mapping between differentiating properties and variant components and, minimal degree of coupling of variant components to other components.

Platforms are generally described to be of one of either two kinds: (1) the module based (discrete) characterised by sets of components being clustered into interchangeable modules that together form the product, or, (2) the scalable platform that becomes adaptable due to letting some of the design variables vary (Simpson 2004). Modularity is proposed as the main enabler for customization (Hvam et al. 2008). Bonev (2015) states that modular architectures are a major enabler for being able to reduce the internal variety of organizations through standardization, while having high external variety towards the market. This is typically done by using a set of common components which are shared between product variants at the same time as varying distinctive components (variant components) to produce product variants which are differentiated by the market. André et al. (2017) introduce a design platform that should support the development of customised products, where coherence across all disciplines is emphasised.

Within the IGLC community several studies regarding modularisation have been reported including, Lennartsson and Björnfot (2010) proposing modular building services, Björnfot and Stehn (2004) argued that modularity support the practice of Lean Production in construction and Bertelsen (2005) try to allocate work groups using a modular mindset. Jensen et al. (2009) used modularity principles to develop a flexible building system within industrialised housing. Further, both Jensen et al. (2013) and Kalsaas (2013) have investigated configurators and their applicability as knowledge carriers.

\section{PRODUCT DEVELOPMENT WITHIN INDUSTRIALIZED HOUSE-BUILDING}

Lessing (2006) defines industrialized house-building as a thoroughly developed process with a well-suited organization for efficient management. The production system is process-oriented with defined value streams, repetitive operations and experience feedback (Johnsson and Meiling 2009). Thus, a move towards industrialized housebuilding means a shift from strictly project based production to a more process-oriented production (Jonsson 2017). Competitiveness is driven from factors such as flexibility, delivery time predictability, quality level and cost (Jonsson and Rudberg 2014). The process is vulnerable to misinformation and a core competence is to master the difference between commonality and distinctiveness (Jansson 2013). 


\section{RESULTS}

The results presented are a synthesis of the gathered data. First an overview of the product development process is presented, and then the four assets of product platforms introduced by Robertson and Ulrich, (1998) is highlighted.

\section{PRODUCT DEVELOPMENT}

The current state of practice in the case company is that they have developed a modular product methodology, in terms of a Technical Platform (TP), see Fig. 2. There is no explicit product development process at the company. Rather, product families and house models, based on the building system and previous house models, are developed to meet the needs from the market. Thus, the product development is managed by sellers and architects. Consequently, customizations are allowed by the client, where a rule of thumb is to keep the balance on $75 / 25$ catalogue house/customization, but there is no distinction when a remodelled standard becomes a variant.

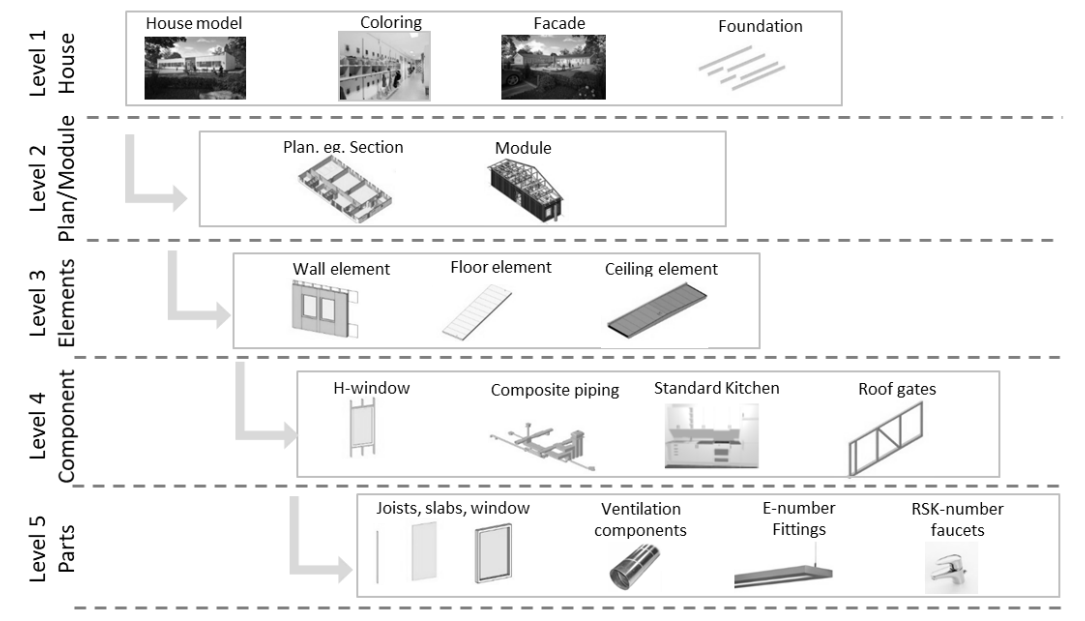

Figure 2: The Technical Platform (TP) and the five levels, house, module, elements, components and commodities.

Though the primary focus is on the house models, development also includes details and technical systems, where development is carried out as illustrated in Fig. 3. It follows the principles from Lessing (2006), meaning that customer specific solutions are derived from existing house models and implemented into the projects. Validation and prototyping is done in real projects, as the technical manager stress "we are a construction contractor". If similar solutions have been used in multiple projects, these can be incorporated into the TP. Assessment of solutions is based on the building system definition.

\section{COMPONENTS}

In fig. 2, the TP is illustrated from top level 1 describing the house down to level 5 which is based on parts. The superior level is described by parts from the next subordinate level. The platform is dependent on the developed house models and how these can be decomposed. Technical demands are divided into 10-15 technical departments, which are 
defined by the company but also the client. Technical development includes all parts of the TP, which should be updated on demands, norms and rules of the construction sector.

Development is initiated reactively, e.g. a problem is reported or demands on costcuts or regulations emerge and an (1) investigation is started that covers all departments, followed by (2) resource allocation and (3) drawings update in the CAD-system. The development project is guided by the impact and the consumption of resources. No other software, beside energy calculations, to model the products than Revit is used. The TP is vulnerable to volatile and changing demands that initially are not clearly stated and specified. For instance, demands on energy, which also varies for different municipalities. To comply with these demands the internet and databases are used.

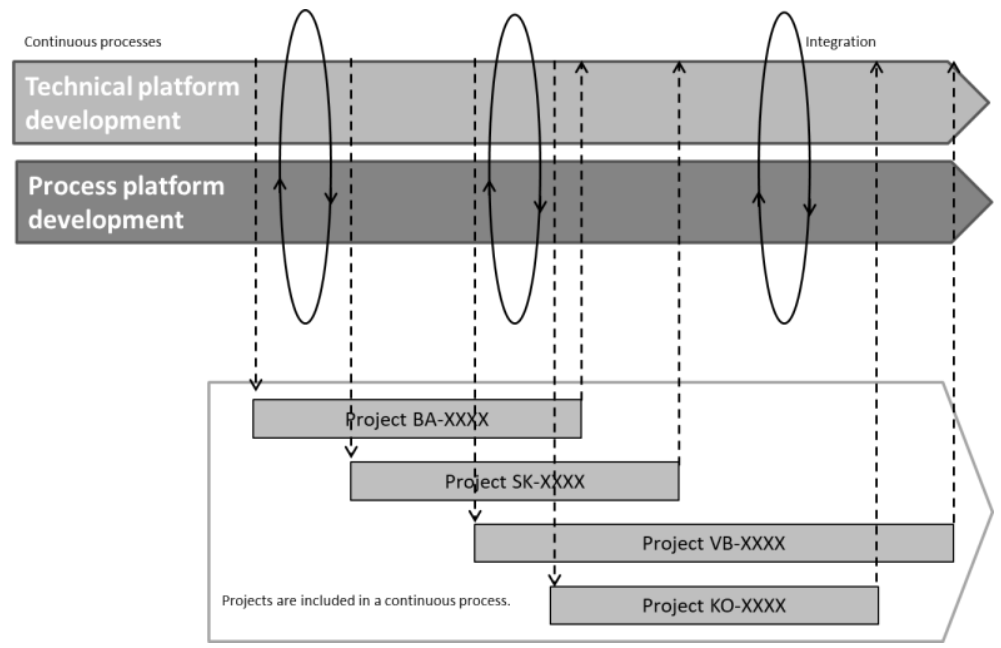

Figure 3: The development of the TP (Green flows) aligned to the on-going projects

(Grey boxes). Company internal illustration inspired by Lessing, (2006).

\section{PROCESSES}

To manage operations, the company has defined an overall process, describing marketing, sales, project management, tendering and purchasing, but also continuous improvements and the development of the TP. The domains have assigned responsibilities and their own subprocesses. For the production process, it is well-described in terms of value flows and order of the work stations and focus on waste elimination and Lean production. However, when taking the TP into consideration, the production layout and process is prioritized over the ability to configure products.

\section{KNOWLEDGE}

The use of design templates and standard operations (STD) lay the foundation of knowhow, but there are also test reports and energy simulations that add to the experience. However, according to the technical manager, the TP is not really defined or fully documented. No metadata is attached to the documents that offers possibilities of better alignments or revision management. Consequently, an overview and holistic approach is missing. Instead, the TP is functioning as a knowledge repository and a substantial part of the contents reside within minds of the staff. The document analysis shows that the number of documents within the TP has been allowed to increase uncontrollably, 
resulting in a folder structure exceeding 1.5 million documents. This is a result from the fragmentation of the TP and the unclear interfaces between the levels of the TP resulting in an increase of variants and evidently the number of documents as well. A similar situation prevails in production where knowledge is buried in the heads of the staff and the reward goes to the problem solvers, which aligns with Löwstedt (2017) and the current state of the construction sector.

\section{PEOPLE AND RELATIONSHIPS}

This asset has not been the primary focus of this paper. However, the interviews with the HVAC coordinator and the electricity coordinator show that development across disciplines is scarce meaning that development is carried out individually. Supplies and material deliveries are not planned according to the structure of the TP, rather than when long lead times demand early purchasing, e.g. windows.

\section{DISCUSSION}

The current state of practice in the case company is that they have developed a modular product methodology. With the TP, the company wants to be competitive using a product platform in the business model, which should bring order to the product development of what can be agreed with the clients. The assets [components, processes, knowledge, people and relationships] described by Robertson \& Ulrich (1998) are fairly welldescribed in the case with (1) a modular structure of the product, (2) a well-described production process, and (3) know-how. The fourth asset [people and relationships] was not in focus. Still, the way some of the product development is carried out, i.e. lack of cross-disciplinary coordination, improvement areas can be identified.

However, when scrutinizing the way that the company manages the balance between distinctiveness and commonality (Robertson and Ulrich, 1998) it becomes evident that there are parts missing. The expansion of the number of documents in the database along with the testimonials from the interviews where a holistic view is missing. When analysing the tool-kit provided by Krause et al. (2014) with the collected data, it can be concluded that; (1) there is no clear distinction between standard components and variant components, (2) no reduction of the variant components to the carrier of differentiating properties, (3) one-to-one mapping between differentiating properties and variant components is missing and (4) the degree of coupling of variant components to other components is unclear.

The results align with the findings from, Jansson (2013) stressing that when an ETO strategy is applied, the balance between distinctiveness and commonality is crucial to master and that it is difficult to apply platforms for an ETO-based context and integrated product architecture (Jensen, 2014). Technical solutions that are developed in specific projects often have integral product architectures that are difficult to re-use in continuous improvement processes (ibid), which matches the situation in the case company. Jansson (2013) proposes a framework to develop a platform strategy for industrialised housebuilding where experience feedback from the supply chain is utilised and incorporated 
into the platform, a strategy that follows the principles of Lessing (2006) and the current way of working with improving the TP of the case company (fig. 3).

The ambiguity in the description of the TP leads to the fragmentation and an unrestrained growth of the document database. For products within the ETO-oriented production strategy working with fluctuating requirements this is not surprising and similar findings have been observed previously (Jansson 2013; Jensen 2014). As André et al. (2017) stated, for platforms in an ETO-context, coherence across all disciplines in needed, which aligns with the basic principles of lean where long-term strategy and holistic view are cornerstones. Modularisation offers an entry to efficiency but active work in all domains is necessary. From both the platform perspective but also from a lean perspective the management of knowledge is a liability since it represents a cornerstone in both fields.

The indistinctive product development and supporting organisation combined with the prevailing culture in construction prioritise projects which clash with the fundament of the industrial housing case. Johnsson (2013) suggests that contractors with a wider scope could focus on standardization of processes rather than products which is consistent with the situation of the ETO process where very few components can be produced before being ordered, which is necessary for creating economies of scale in production (Jensen 2014).

Properly applied, the TP should facilitate lean both in design and production. Fundamental lean principles such as lead time reduction, variability management, and continuous improvements are enhanced from a well-defined platform. However, since Lean is applied in the production, there is a risk linked to the current state with a multitude of variants accepted by the sales department, i.e. having a modular product structure without boundaries is a risk when the number of variants is allowed to expand (Höök 2008) and applying lean principles on non-standard operations might be counterproductive. Conversely, increasing pre-definitions, the risk is to move too far away from the demands of the clients and the market, leading to an imbalance between buildability and client satisfaction (Jansson 2013), including product definitions (Brege et al. 2014), design boundaries (Jansson 2013) and the production (Lennartsson 2012). Thus, there is a risk bundled if Lean is introduced without any evaluation.

\section{CONCLUSIONS}

The aim of this paper was to analyse current strategies and support to master the balance of external and internal efficiency in product development within industrialized housebuilding to facilitate the development of a product platform strategy. The data analysis through the lens of the assets provided by Robertson \& Ulrich (1998) identifies several gaps between the state-of-practice and theory on platforms, both generically and regarding research within the industrialised house-building sector. The instrument used to balance external and internal efficiency is the Technical Platform. The results show that customised solutions outside the boundaries of the TP are allowed, e.g. a large number of variants in the product offer and a sliding document database. Having a large portion of public clients with specific demands reinforce this situation. The absence of a holistic 
view on the operations obscures the potentials of modularisation prescribed in the TP. In conclusion, there is an imbalance where external efficiency is prioritized over the internal efficiency, which clashes with Bonev (2015).

\section{PATH FORWARD}

The results show that the case company needs to become better in the management of distinctiveness and commonality from a platform strategy perspective. In alignment with the TP and lean philosophy regarding knowledge handling, the file system database needs to be mapped and sorted out in terms of what information is included in the different drawings and files, identification of systems running across different levels of the TP. The range of documents can then be reduced, and redundant variants can be excluded. Further, an increased integration between the different parts of the platform should be facilitated.

\section{ACKNOWLEDGEMENTS}

The authors would like to express gratitude to the involved company, making this research possible, as well as to the The Region Jönköping County for funding this research.

\section{REFERENCES}

André, S., Elgh, F., Johansson, J., Stolt, R., (2017). The design platform - a coherent platform description of heterogeneous design assets for suppliers of highly customised systems. Journal of Engineering Design 28(10-12), 599-626

Bertelsen, S. (2005) Modularization - A Third Approach to Making Construction Lean? Proc. $13^{\text {th }}$ Conf. of the Intl Gr for Lean Constr., Sydney, Australia.

Björnfot A. \& Stehn, L. (2004) Industrialization of Construction - A Lean Modular Approach. Proc. $12^{\text {th }}$ Conf. of the Intl Gr for Lean Constr., Copenhagen, Denmark.

Bonev, M. (2015). Enabling Mass Customization in Engineer-To-Order Industries: DTU Management Engineering.

Brege, S., Stehn, L. \& Nord, T. (2014). Business models in industrialized building of multi-storey houses. Construction Management and Economics. 32(1-2): 208-226.

Gosling, J. and Naim, M.M. (2009) Engineer-to-order supply chain management: a literature review and research agenda. Int. J. of Prod. Economics, 122 (2), 741-54.

Gosling, J., Naim, M.M. \& Towill, D. (2013). A supply chain flexibility framework for engineer-to-order systems. Prod. Plan. \& Control: The Mgmt. of Op., 24(7), 552-66

Höök, M. (2008). Lean Culture in Industrialized Housing - a study of Timber Volume Element Prefabrication. Doc diss. Luleå University of Technology. Luleå, Sweden.

Hvam, L., Mortensen, N. H., \& Riis, J. (2008). Product customization: Springer Publ.

Jansson, G. (2013). Platforms in Industrialised House-Building. Doc diss. Luleå University of Technology. Luleå, Sweden.

Jensen, P., Hamon, E. \& Olofsson, T. (2009). Product Development Through Lean Design and Modularization Principles. In:, Cuperus, Y. \& Hirota, E.H., 17th Annual 
Conf. of the Intl Group for Lean Construction. Taipei, Taiwan, 15-17 Jul 2009. pp 465-474

Jensen, P., Larsson, J., Simonsson, P. \& Olofsson, T. (2013). Improving Buildabuility With Platforms and Configurators. In:, Formoso, C.T. \& Tzortzopoulos, P., 21th Annual Conference of the International Group for Lean Construction. Fortaleza, Brazil.

Jensen, P. (2014). Configuration of Platform Architectures in Construction. Doc diss. Luleå University of Technology. Luleå, Sweden.

Jensen, P., Olofsson, T. \& Johnsson, H. (2012) Configuration through the parameterization of building components. Automation in Construction, 23, 1-8.

Johnsson, H. (2013). Production strategies for pre-engineering in housebuilding: exploring product development platforms, Constr. Management \& Economics, 31(9), 941-958.

Johnsson, H. \& Meiling, J. H. (2009). Defects in Offsite Construction: Timber Module Prefabrication. Construction Management and Economics, 27(7), pp. 667-681.

Johnsson, H. (2011). The building system as a strategic asset in industrialized construction. The 6th Nordic Conf. on Construction Managem. \& Org, 14-16. Copenhagen, Denmark

Jonsson, H. \& Rudberg, M. (2014). Classification of production systems for industrialized building: a production strategy perspective. Constr. mgmt and Eco., 32(1-2), 53-69.

Jonsson, H. (2017). Production Strategy in Project Based Production within a HouseBuilding Context. (Doc. diss). Linköping: Linköping University Electronic Press.

Kalsaas, B.T. (2013). Improving Buildabuility With Platforms and Configurators. In: Formoso, C.T. \& Tzortzopoulos, P., $21^{\text {st }}$ Conf. of the Intl Gr for Lean Constr.. Fortaleza, Brazil, 31-2 Aug 2013. pp 659-668

Konijnendijk, P.A. (1994) Coordinating marketing and manufacturing in ETO companies. International Journal of Production Economics, 37, 19-26.

Krause, D., Beckmann, G., Eilmus, S., Gebhardt, N., Jonas, H., \& Rettberg, R. (2014). Integrated development of modular product families: a methods toolkit. In Advances in Product Family and Product Platform Design (pp. 245-269): Springer.

Lennartsson (2012). The Transition of Industrialised House-Building Towards Improved Production Control. Doctoral thesis. Luleå University of Technology. Department of Civil and Environmental Engineering. Luleå, Sweden.

Lennartsson, M. \& Björnfot, A. (2010). Step by-Step Modularity - a Roadmap for Building Service Development. Lean Construction Journal, 2010(1), pp. 17-29.

Lessing, J. (2006). Industrialised House-Building. Licentiate Thesis, Dep. Construction Sciences. Lund University, Lund, Sweden.

Lessing, J., Stehn, L. \& Ekholm, A. (2015). Industrialised house-building-development and conceptual orientation of the field. Construction Innovation, 15, 378-399.

Löwstedt, M. (2017). Hur sker förändring inom svensk byggbransch? En studie om initiativ, logiker, och roller (In Swedish). SBUF, Projekt-ID 12509.

McGrath, M. (1995). Product strategy for high-technology companies. NY: Irwin publ. 
Meyer, M. \& Utterback, J. (1993). The product family and the dynamics of core capability, Sloan management review, 34(3), 29-47.

Meyer, M. H., \& Lehnerd, A. P. (1997). The power of product platforms - Building value and cost leadership. New York: The Free Press.

Miles, M.B. \& Huberman, A.M. (1984). Qualitative Data Analysis: A Sourcebook of New Methods. 1st Ed., SAGE Publications Inc., California

Muffatto, M. (1999). Introducing a platform strategy in product development. International Journal of Production Economics, 60, pp 145-153.

Robertson, D., \& Ulrich, K. (1998). Planning for product platform. Sloan mgmt rev, 1931.

Simpson, T. W. (2004). Product platform design and customization: status and promise. Artificial Intelligence for Engineering Design, Analysis and Manufact., 18(1), 3-20.

Simpson, T. W., Z. Siddique, \& J. Jiao. (2006). Product platform and product family design - Methods and application. New York: Springer science+Business media, inc.

Thuesen, C. \& Hvam, L. (2011) Efficient on-site construction: learning points from a German platform for housing. Construction Innov.: Information, Process, Management, 11(3), 338-55. 